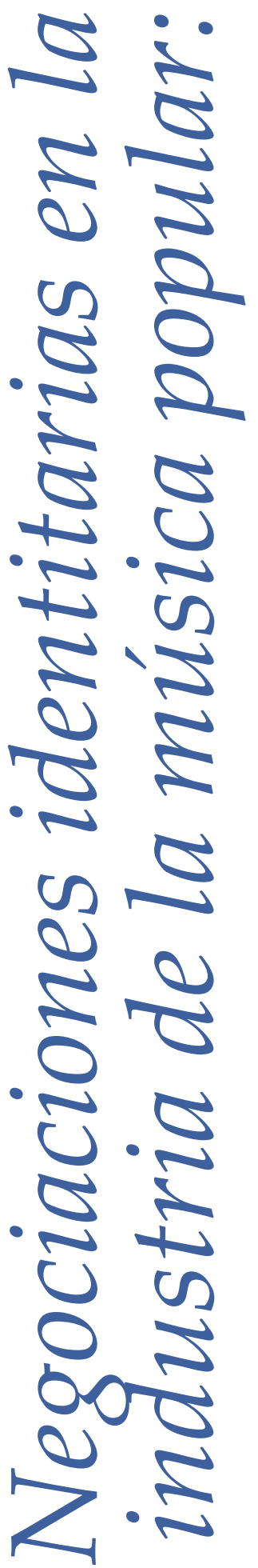

\title{
la evolución del
} repertorio de un cantante del folklore argentino
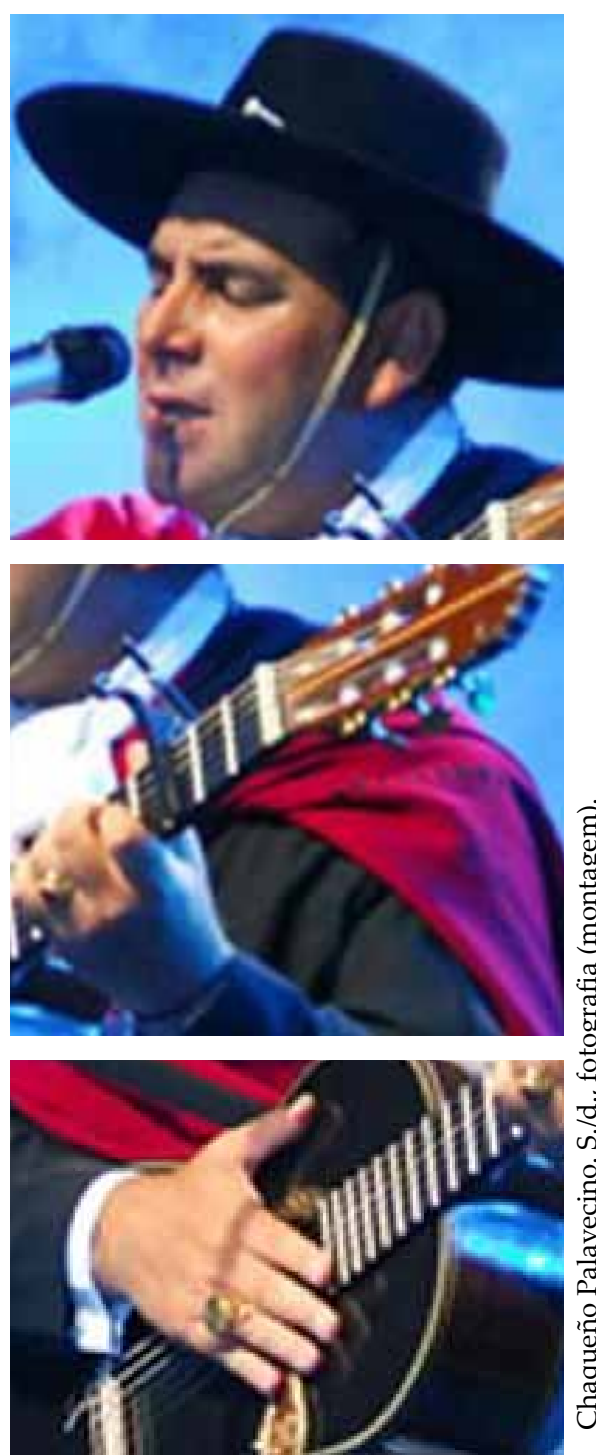

\section{Ricardo J. Kaliman}

PhD em Literatua pela University of Pittsburgh (EUA). Professor da Facultad de Filosofía y Letras da Universidad Nacional de Tucumán (UNT). Pesquisador do Consejo Nacional de Investigaciones Científicas y Técnicas (Conicet/Argentina). Autor, entre outros livros, de Sociología de las identidades: conceptos para el estudio de la reproducción y la transformación cultural. Villa María: Eduvim, 2015. Rkaliman8@gmail.com 
Negociaciones identitarias en la industria de la música popular: la evolución del repertorio de un cantante del folklore argentino

Identity negotiations within the industry of popular music: the development of the repertoire of an Argentine folkloric singer

Ricardo J. Kaliman

\section{RESUMO}

La incorporación de"Amor salvaje", a mediados de los 1990, supuso una ruptura en la estructura hasta entonces predominante en el repertorio del Chaqueño Palavecino y acompañó el momento de su consagración como estrella en el marco de la industria del folklore musical argentino. En este trabajo, se abona la hipótesis de que la pieza marcó el comienzo de una negociación entre el perfil criollista y tradicional y las apetencias de un público más amplio. Antes de examinar las significaciones de las transformaciones que la canción implicaba en su género musical, por un lado, y en el tono y los presupuestos morales de su letra, por otro, se da cuenta brevemente de los rasgos históricos del discurso identitario criollista y del modo particular en que este es adoptado en la imagen y la práctica del Chaqueño Palavecino. PALAVRAS-ChAVE: folklore argentino; Chaqueño Palavecino; industria cultural.

\section{ABSTRACT}

The incorporation of the piece named "Amor salvaje", in the middle 1990, meant somewhat of a breakdown within the up to that moment prevailing structure of the repertoire of Chaqueño Palavecino and went along with the moment of his recognition as a major star within the industry of argentine folkloric music. In this paper, the hypothesis is sustained that the piece marked the beginning of some negotiation between a criollista and traditional profile and the aspirations of a broader audience. Before examining the meanings of the transformations the piece involved both in its musical genre and its tone y moral assumptions, a brief account is offered about the historic traits of criollista identity discourse and the particular way in which it is adopted in the image and practice of Chaqueño Palavecino.

KEYwords: Argentine folklore; Chaqueño Palavecino; cultural industry.

En 1997, el Chaqueño Palavecino, ya en ese momento una figura en indiscutible ascenso en la industria del folklore musical argentino, publicó su séptimo disco, en el que incluyó la canción "Amor salvaje", un carnaval cruceño que relata un fogoso encuentro sexual, en un ámbito marcadamente silvestre, entre una hombre y una mujer que no se han conocido antes y no proyectan volver a verse.

Ya antes de grabada, esta pieza era una de las más requeridas por sus seguidores, y aun hoy, más de veinte años después, la repite ineludiblemente en cada una de sus presentaciones, con una acogida jubilosa de un público que la corea masivamente mientras ondea sus brazos o baila, y sigue haciéndolo mientras el Chaqueño culmina la ejecución reinician- 
do una y otra vez el estribillo. No fue mucho tiempo después de aquella grabación que el Chaqueño llegó a adquirir el status más alto de la carrera profesional de un cantante popular, el de estrella indiscutible, incluso la más encumbrada por momentos a lo largo de la década siguiente, en la industria del folklore argentino, según puede colegirse de la convocatoria a sus recitales y la venta de sus discos. ${ }^{1}$ Por cierto, la incorporación de "Amor salvaje" no puede considerarse la causa de ese encumbramiento, pero no cabe duda de que lo acompañó y jugó un papel importante en ese proceso. Sigue siendo hasta el día de hoy una de sus piezas emblemáticas, una de aquellas con las que lo identifican recurrentemente tanto el periodismo como el público del folklore argentino en general, incluidos sus detractores.

Sin embargo, el Chaqueño demoró cierto tiempo en llevarla al disco. Cuando por fin lo hizo, ya hacía por lo menos un par de años que había comprobado la resonancia de su interpretación de este tema y su público más fiel la reclamaba permanentemente en sus presentaciones en vivo. Sostuvo entonces ante la prensa que la postergación se había debido a que no era el tipo de canciones que él solía cantar, una de las muchas afirmaciones que se han reproducido intermitentemente en ese particular eco que se abre camino a través de los comentarios periodísticos y las salas de chat.

La incorporación de la canción en el repertorio, sin embargo, no resultó una trasgresión momentánea, sino, como trataré de mostrar en este trabajo, una reorientación significativa en la estructura de su repertorio, que a partir de este momento comenzó a incluir otras piezas de similares funciones. "Amor salvaje", en efecto, conlleva significaciones que turbaban el proyecto original del cantor. Su incorporación supuso no tanto un cambio de rumbo absoluto con respecto a ese perfil básico, sino más bien una síntesis negociada con las disposiciones generales de su creciente público. El examen de todo este proceso ilustra la importancia de la consideración de las identidades populares en el estudio de la dinámica de las industrias culturales, y al mismo tiempo sugiere importantes propuestas en torno al complejo juego que se establece entre ellas y otros factores sociales de esa dinámica. En particular, sugiere los contornos de la configuración de la identidad criollista que podríamos llamar "tradicional" en la sociedad argentina actual y suscita hipótesis sobre las características de un público más amplio de ese mismo folklore en el que esa versión del criollismo sigue jugando un papel, pero de una manera solapada frente a otras inquietudes culturales.

Según el análisis que desarrollaré a continuación, las innovaciones anunciadas por "Amor salvaje" en la estructura hasta entonces predominante en el repertorio del Chaqueño Palavecino se dieron fundamentalmente en dos niveles: en el género musical, por un lado; y en el tono y la temática de la letra, por otro. En ambos casos, sin embargo, lo que afectaban era el perfil característico y predominante que el intérprete venía cultivando, que podemos llamar "criollista". Por este motivo, antes de examinar las transformaciones que la pieza implicaba en cada uno de los dos aspectos mencionados, me detendré a dar cuenta brevemente de los rasgos históricos del discurso identitario criollista y del modo particular en que este es adoptado en la imagen y la práctica del Chaqueño Palavecino.

\section{Criollismo e industria cultural}

El circuito del folklore comercial comienza a cobrar cuerpo en la so-

${ }^{1}$ En 1998, en efecto, obtuvo el premio Consagración en el Festival de Cosquín, lauro que simboliza un reconocimiento al mismo tiempo de la industria, del público y del periodismo en el nivel nacional. 
${ }^{2}$ Cf. LATTES, Alfredo E. \& RECCHINIDE LATTES, Zulma L: Migraciones en la Argentina: estudio de las migraciones internas e internacionales, basado en datos censales, 1869-1960. Buenos Aires: Editorial del Instituto Torcuato Di Tella, 1969.

${ }^{3}$ Cf. PUJOL, Sergio. Historia del baile: de la milonga a la disco. Buenos Aires: Emecé, 1999.

${ }^{4}$ Ver un excelente informe sobre la inserción de la radio en la cultura argentina en MATTALLANA, Andrea. Qué saben los pitucos: la experiencia del tango entre 1910 y 1940. Buenos Aires: Prometeo, 2008.

${ }^{5}$ Aunque los atisbos iniciales de esta tendencia ideológica pueden rastrearse ya en las últimas décadas del siglo XIX. Ver CHEIN, Diego. La invención literaria del folklore: Joaquín V. González y la otra modernidad. Tucumán: Universidad Nacional de Tucumán, 2007.

${ }^{6}$ Ver una versión más desarrollada del análisis de este contexto histórico en KALIMAN, Ricardo J. Alhajita es tu canto: el capital simbólico de Atahualpa Yupanqui. Córdoba: Comunicarte, 2004.

${ }^{7}$ Ver PRIETO, Adolfo. El discurso criollista en la formación de la Argentina moderna. Buenos Aires: Sudamericana, 1988. ciedad argentina durante las primeras décadas del siglo XX, como resultado del impulso de los migrantes de las zonas rurales del interior del país hacia Buenos Aires por reproducir las costumbres que les eran familiares y que les proporcionaban un sentido de seguridad y comunidad. En el contexto de esta concentración de una relativamente alta población enlazada por inquietudes comunes ${ }^{2}$, se fue gradualmente constituyendo un mercado que se canalizó inicialmente en los lugares bailables donde convivían con otras manifestaciones populares y en las peñas que organizaban las asociaciones de residentes provincianos ${ }^{3}$, y no mucho después en las radios y en el disco. ${ }^{4}$ El desarrollo de esta industria se vio reforzado y estimulado por el apoyo ideológico de un discurso que se había generalizado entre algunos intelectuales de los sectores acomodados de la sociedad argentina, heredero del proyecto, que cobrara particular fuerza en las primeras décadas del siglo XX, de erigir a la vida campesina en emblema de la unidad espiritual de la nación. ${ }^{5}$

Las motivaciones históricas que subyacen a este giro de la hegemonía terrateniente son conocidas: a comienzos del siglo $\mathrm{XX}$, la oligarquía pampeana comenzaba a percibir que los cambios sociales que había traído la modernización se estaban configurando como una amenaza contra su secular hegemonía. En lo ideológico, su reacción consistió en construirse a sí mismos como los señores naturales del territorio, reivindicando al campo, donde su poder seguía siendo indiscutible, como el reservorio de la esencia misma de la nación. ${ }^{6}$ Los motivos característicos de la versión hegemónica de este discurso identitario fueron formulados por los intelectuales orgánicos de la oligarquía, con más nitidez y proyección a partir de la conocida como generación del Centenario. Sin embargo, este discurso resemantizaba o reorganizaba, en muchos casos, signos propios de prácticas y manifestaciones de diverso orden, originadas en aquellos sectores populares que, precisamente, aspiraba a hegemonizar.

En efecto, aunque pueden argumentarse lazos históricos con adscripciones identitarias ya vigentes en el período colonial y de las primeras décadas postcoloniales, la configuración de la identidad criolla que se volverá relevante para comprender los procesos sociales que aquí nos interesan cobró cuerpo durante la segunda mitad del siglo XIX entre amplios sectores populares que iban gradualmente ocupando espacios en las periferias urbanas, y pareció irse moldeando como contrapeso del imaginario de los intelectuales de las élites dominantes durante el período conocido como el de la "organización nacional", cuya desvalorización de la población local se traducía en - y legitimaba - atropello de sus derechos civiles que, por otra parte, el propio discurso liberal, sin embargo, les acordaba. Las manifestaciones de la identidad criolla emergentes a lo largo de este período, consecuentemente, presentaban una fuerte impronta de clase, con un énfasis en la apología de las compensaciones simbólicas frente a las arbitrariedades del poder, como en las coplas populares que ensalzaban a los cuatreros; o en el reclamo contra esas injusticias, en un tono vindicatorio, por ejemplo, en el folletín Juan Moreira, de Eduardo Gutiérrez (cuya popularidad escandalizara a los intelectuales de los sectores dominantes) y por lo menos justificativo en el Martín Fierro de José Hernández. ${ }^{7}$ Los intelectuales de la oligarquía, al incorporar este discurso, desestimaron, como es de esperarse, los aspectos contestatarios, pero conservaron siempre la referencia a los sectores populares.

La identidad criolla es, en principio, una identidad étnica, en la me- 
dida en que en ella confluyen consideraciones "raciales" y culturales. El discurso oligárquico se esforzó explícitamente, por ejemplo, en dejar afuera de su construcción al indio (que podía reclamarse como legítimo hijo del territorio) y al inmigrante (en quien se depositaban las culpas de procesos sociales como la industrialización y el sindicalismo, dos de las principales amenazas contra la hegemonía terrateniente). Sin embargo, la etnicidad constituyó un rasgo inestable de la identidad criolla. Ya en configuraciones de esta identidad activas durante la segunda mitad del siglo XIX, aparecía como admisible lo que podemos llamar el "acriollamiento", la adscripción de individuos de otro origen étnico a través de la adopción de los rasgos fundamentales del grupo. De hecho, una de las vías más eficaces de difusión de la figura de Juan Moreira fue su representación en el circo criollo de los hermanos Podestá, de origen italiano.

Un rasgo que participa de la identidad criolla a todo lo largo de este proceso es su vinculación con la vida rural, que persiste y sigue siendo característicamente definidora aun cuando pasa a generalizarse $-\mathrm{y}$, de hecho, puede decirse que cobra una dimensión sociológica relevante- en sectores urbanos. En consistencia con el contexto en el que surge, la reformulación hegemónica de las primeras décadas del siglo XX enfatizaba particularmente esta propiedad, a través de la construcción de una imagen del gaucho, al que elevan como estandarte de la nacionalidad. A las virtudes como el coraje, el honor, la lealtad en la amistad, que ya podían reconocerse en las versiones del criollismo popular del siglo anterior, los intelectuales del Centenario, en particular la influyente versión de Lugones, agregaron otras, como la galantería con la dama y el pudor en la expresión de los sentimientos. ${ }^{8}$

El surgimiento de la industria del folklore musical se nutrió de esta alianza de intereses. Los sectores sociales ligados efectiva o emotivamente con los terratenientes de diversas latitudes del país, que se representaban a sí mismos como la versión más granada del criollismo esencial, proporcionaron muchos de los intérpretes más promocionados de las primeras generaciones de la industria. Al mismo tiempo, muchos intérpretes de origen campesino, semi-campesino, o popular en un sentido general, asumieron como propio el esencialismo encarnado en ese discurso, que, aunque apuntaba de diversas maneras a la subordinación de su clase, al mismo tiempo asignaba a sus propias prácticas en un valorado capital simbólico. Esta dualidad de clases, que constituye una de las tensiones más dinámicas de la identidad nacional criolla, ha signado correspondientemente muchas de las variedades de la industria del folklore musical a lo largo del siglo XX.

El discurso identitario criollo es no sólo una marca de nacimiento del folklore comercial argentino, sino que lo ha acompañado en su casi centenaria trayectoria, a pesar de las variadas vicisitudes que esta práctica ha experimentado a través del tiempo, en función de las transformaciones sociales e ideológicas de la sociedad argentina, así como de la diversificación de su público. Los motivos característicos del discurso identitario criollista que acabo de reseñar siguen acompañando sistemáticamente sus diversas manifestaciones, emergiendo en la palabra de los locutores de festivales y de programas de radio y televisión, de periodistas de diarios o de revistas especializadas, y, por cierto, en la de muchos de los propios intérpretes. En muchos de los casos, sin embargo, este discurso funciona como un punto de referencia al que parece recurrirse como una pauta codificada de la práctica, pero que se dispersa en una constelación de reinterpreta-

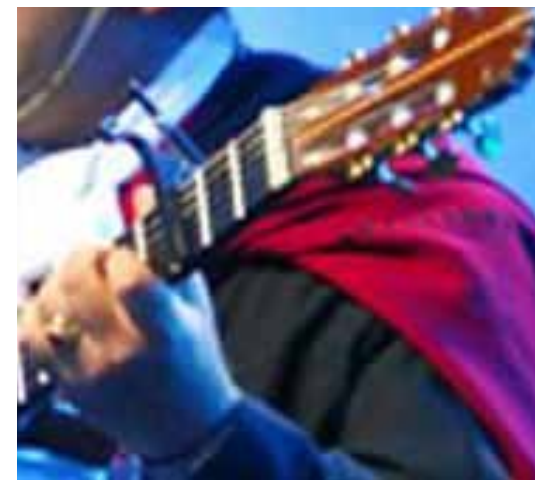

${ }^{8}$ Ver LUGONES, Leopoldo. El payador. Caracas: Biblioteca Ayacucho, 1979 [1916]. 
${ }^{9}$ Las conclusiones ofrecidas en este trabajo se basan, por una parte, en análisis de textos y de la estructura del repertorio del Chaqueño y en la reconstrucción histórica a partir de documentos y bibliografía, pero también en un trabajo de campo consistente en observación participante en festivales de folklore y entrevistas semiestructuradas a una veintena de seguidores del Chaqueño Palavecino, participaciones en foros virtuales dedicados a este cantor y entrevistas semiestructuradas a cinco productores de la industria musical. La mayor parte de este trabajo de campo fue desarrollado entre enero de 2005 y 2008. ciones que se pueden descubrir en la sutileza de ciertos énfasis, omisiones o re-semantizaciones, o incluso en las tensiones o contradicciones que se dan entre ese discurso y los signos que se ponen en juego en la práctica misma. La desaparición de las condiciones que dieron lugar y sentido a la configuración de sus motivos característicos proporcionan sin duda una parte de la explicación para estos sutiles pero cada vez más evidentes distanciamientos. Sin embargo, la imagen pública y muchos de los rasgos performativos del Chaqueño Palavecino parecen recuperar los perfiles característicos del más tradicional discurso criollista, lo cual no ha impedido sin embargo un estrellato indiscutible. Al mismo tiempo, las negociaciones identitarias que, según postulo aquí, cristalizaron a partir de la incorporación de "Amor salvaje" a su repertorio, constituyen un síntoma sobre las condiciones actuales de esa perspectiva tradicional en la sociedad argentina.

\section{El criollismo del Chaqueño Palavecino}

La historia del vestuario con el que los intérpretes del folklore comercial argentino se presentan ante su público proporciona ciertos índices de las cambiantes tomas de posición frente a los motivos clásicos del discurso identitario criollo. Uno de los signos de la incorporación al circuito de un importante sector de una clase media ilustrada durante la década de los 60 , por ejemplo, fue el gradual abandono de las distintas vestimentas que se consideraban características del gaucho y que habían sido altamente preferenciales en la escena del folklore por lo menos desde los 40 (sólo renunciable frente al traje y corbata que rendía tributo a la etiqueta de la elegancia pública urbana). Durante un cierto período, la elección del vestuario gauchesco se convirtió en signo de una opción relativamente más conservadora y tradicionalista. Sin embargo, para la década de los 1990, había adquirido una generalizada connotación anacrónica, como lo ilustra el caso de los Nocheros cuya decisión de abandonar las prendas camperas no se interpretó como una posición contestataria, sino como parte de un comprensible esfuerzo por representar al público juvenil con el que se identificaban. En este contexto, el lujoso traje de gaucho, con un ancho sombrero negro que constituye una de las marcas distintivas del Chaqueño Palavecino, resultó particularmente llamativo. Desde los últimos años del siglo XX, el Chaqueño era la única figura estelar que usaba este tipo de vestimenta en el festival nacional de folklore de Cosquín, la reunión más importante y representativa de la industria.

Al proponer explicaciones del éxito del Chaqueño Palavecino, los productores de la industria del folklore son conscientes de que este intérprete cubre las expectativas de una cierta franja del mercado. ${ }^{9}$ Es casi un lugar común entre ellos sostener que había venido a ocupar el vacío dejado por otros intérpretes, entre los que mencionan figuras como Las Voces de Orán y Horacio Guarany, relativamente dispares entre sí pero que presentan ciertos rasgos comunes en cuanto al perfil del público. En mis entrevistas con los seguidores del Chaqueño, sin embargo, estas continuidades no parecen confirmarse, por lo menos conscientemente. Ciertamente, algunos de ellos establecen relaciones de ese tipo, pero, en líneas generales, lo que predominantemente tienden a subrayar remite a los signos característicos del discurso criollista: la vestimenta de gaucho, por un lado, así como la persistencia en los instrumentos musicales tradicionales, en oposición a la recurrencia a otras opciones de sonoridad que marcan una distancia con 
el origen rural. Estas diferencias que pueden generalizarse entre ambos grupos de informantes son fácilmente atribuibles a las distintas motivaciones con que cada grupo se articula en el campo del folklore, pero al mismo tiempo permiten avizorar una interesante convergencia: mientras la perspectiva de los empresarios cifra al público del Chaqueño entre los sectores sociales de bajos ingresos y de menor inserción en la educación formal, el público tiende a poner de relieve su fuerte identificación con los signos más tradicionales del criollismo.

Ambos rasgos, a su vez, son fuertemente enfatizados en la construcción de la imagen pública que el propio Chaqueño transmite y a la que apuntan sistemáticamente tanto la semiótica de sus espectáculos como la de su publicidad, sus entrevistas y su merchandising. Los tópicos recurrentes de su biografía, tanto en sus gacetillas como en los libros que se han publicado sobre su vida ${ }^{10}$, señalan su origen humilde y relacionado con la vida rural: Oscar Palavecino nació en Rancho el Nato, un paraje del Chaco salteño, y trabajó desde niño en una variedad de ocupaciones. Esta localización geográfica y social ha quedado registrada no sólo en su nombre artístico, sino que es también la de algunos de los músicos que lo acompañan -circunstancia que no deja de recordar en algún momento en el transcurso de sus actuaciones - y de muchos de los invitados que hace subir al escenario en las presentaciones con más capacidad de llegada (en los festivales televisados, por ejemplo, o en salas de grandes ciudades). Su región natal, así como los humildes personajes del ambiente rural en que se crió, son el tema predominante en las canciones de su autoría, así como el marco excluyente en un CD que grabó en 2007, en un momento particularmente culminante de su carrera.

La sonoridad misma, cuya naturaleza acústica destacan sus seguidores, en contraste con el uso de guitarras y bajos eléctricos o, por supuesto, batería, que se han generalizado en la mayor parte de los otros intérpretes exitosos, también es destacada como una herencia de ese origen. Hasta mediados de los 2000, la formación que acompañaba al Chaqueño incluía guitarra acústica, bombo, violín y bandoneón. Posteriormente, incorporó un bajo eléctrico y, en algunos momentos, batería. ${ }^{11} \mathrm{~A}$ medida que su creciente éxito le fue demandando mayor volumen sonoro, para mantenerse a tono con las exigencias generalizadas en los festivales masivos, fue aumentando el número de músicos y recurriendo a una tecnología de amplificación más sofisticada, pero sin abandonar la predominancia neta de los instrumentos de base acústica y característicos del folklore bailable de su región natal. En los distintos guiones de sus presentaciones, por otra parte, en varios ciclos reservó un momento para ejecutar coplas de chacarera "a la usanza de mi tierra”, según lo anunciaba, que consistía en reducir el acompañamiento a los bombos y los violines.

Diversos matices perfilan las particularidades de esta flagrante adopción de los signos del discurso identitario criollo. Por una parte, la imagen rural del Chaqueño está levemente teñida de rasgos de modernidad que contribuyen a volverlo creíble y contemporáneo, así como condicen con la servicial apelación a la tecnología. Los datos biográficos sobre los que su imagen redunda, por ejemplo, incluyen su mudanza a Salta en la adolescencia y su trabajo como camionero primero y como chofer de ómnibus después, antes de alcanzar el éxito que ahora le permite dedicarse de lleno al folklore. Su discurso en escena no apela a modismos gauchescos, sino que se mueve dentro de un dialecto coloquial e incluye referencias a objetos

${ }^{10}$ Ver TARRUELLA, Alejandro C. De donde soy: Chaqueño Palavecino. Buenos Aires: Sudamericana, 2008, y DIGIANO, Luis. El Chaqueño Palavecino. Por culpa de ser cantor. Buenos Aires: Corregidor, 2013.

${ }^{11}$ En algunos formatos, el Chaqueño incorporó un momento en que un pianista lo acompañaba en la interpretación de algunas piezas, en general "clásicos" del folklore argentino, por ejemplo piezas de Yupanqui o Castilla-Leguizamón. 
${ }^{12}$ Ver la descripción de este festival en TARRUELLA, Alejandro C., op. cit.

${ }^{13}$ KALIMAN, Ricardo J. El canto de la dicha verdadera. Pueblo y utopía en letras del folklore de los 60 y 70 en Tucumán. In: ORQUERA, Fabiola Orquera (ed.). Ese ardiente Jardín de la República: formación y desarticulación de un campo cultural (Tucumán, 1880-1975). Córdoba: Alción, 2010, y idem, Dos actitudes ilustradas hacia la música popular argentina, a publicarse en Revista Argentina de Musicología, n. 17, 2017. característicos de la vida cotidiana en la ciudad. Por otra parte, aunque no las rehuye, tampoco abunda en las notas esencialistas del discurso identitario más tradicional, que parecen surgir sólo en ciertos momentos, pautadas por el código estandarizado de la propia práctica o por el contexto de ciertas celebraciones patrias.

Estas características se absorben en un principio más general de la construcción de su imagen pública, regida por un esfuerzo de aproximación a cierto sector del público, presumiblemente el que configuró su base inicial de sustentación en el mercado, y que le reconoce ciertas virtudes seleccionadas de entre las que la tradición criollista clásica ensalzara. En los testimonios recogidos, pueden distinguirse, por ejemplo: a) la "guapeza", a partir de la energía que imprime a los recitales: el Chaqueño canta sus temas con gruesa y fuerte voz, casi gritando, aunque sin falsetes ni esfuerzos demasiado visibles; $y$, mientras no canta, se mueve a grandes pasos por todo el escenario, sin disminuir su vitalidad en ningún momento. Son legendarias, y forman parte de su publicidad, sus largas presentaciones, como su tradicional amanecida en la Serenata de Cafayate; b) la ya citada lealtad a su tierra de origen, pero también a la gente de esa zona: según sus seguidores, el Chaqueño es muy generoso en el patrocinio de "jóvenes promesas" del folklore y se hace cargo de todos los gastos de un festival que organiza periódicamente en el Chaco salteño, con ganancias que son destinadas a los hospitales y escuelas de la zona ${ }^{12}$; c) familiaridad en el trato y campechanía: el Chaqueño se dirige al público, cuando habla, en un tono familiar, sin ningún rebuscamiento ceremonial ni pretensiones moralizantes o didácticas en ningún sentido, lo cual le ha valido más de una vez punzantes críticas por las inadecuaciones incluso ofensivas, proferidas en el escenario, con intenciones humorísticas de "dudoso" gusto. No hay una retórica de escenario visible, sino un tono de fiesta compartida, que se refuerza con gestos como el de aceptar un vaso de vino que le alcanzan desde el público.

El estilo interpretativo del Chaqueño, que también apuntala la proximidad con este público, no marca diferencias particulares de interpretación entre una y otra canción. Se limita a decir la letra, con claridad, vehemencia y entonación melódica. Como en muchos otros casos en los que se pone de manifiesto la identidad "popular", por oposición a la que en otros trabajos he llamado la identidad "ilustrada"13, no se pone de manifiesto voluntad de innovación ni mucho menos de efectos experimentales en este aspecto, una propiedad que los seguidores parecen considerar también una virtud. La extracción de clase arriba señalada distingue al Chaqueño de otros intérpretes que también rehuyeron las sofisticaciones cultivadas, como los Chalchaleros, con una imagen más ligada a las modalidades y valores de las clases altas salteñas que a los sectores populares. Esta propiedad se vuelve relevante a la luz de las tensiones arriba señaladas en el seno de la identidad criolla. Rasgos no demasiado sutiles modalizan las respectivas apropiaciones de los signos criollistas. En contraste con la medida y moralizante postura de los Chalchaleros, conjunto que señoreó el folklore comercial durante varias décadas, el discurso del Chaqueño se permite por momentos un humor casi chabacano, incluso en algunos casos rayano con la grosería; y gestos, como el de entrar a caballo o preparar un asado en el escenario, que transgreden las pautas ordenadas del artista profesional. Es a través de estas incisiones que la trayectoria del Chaqueño abre el camino para las negociaciones de su criollismo con las expectativas de un 
público más amplio que el que lo acompañara en sus primeros años de carrera artística.

\section{Que empiece la fiesta. El género musical de "Amor salvaje"}

El conjunto de canciones editadas en discos por el Chaqueño Palavecino hasta 2010 incluía 170 piezas. De entre ellas, más de la mitad (99) se encuadran claramente en las formas canónicas de la zamba y la chacarera. Agrupándolas además con los gatos y escondidos, se conformaba un total de 118 piezas, es decir las dos terceras partes del repertorio publicado. Esta distribución corresponde a un perfil específico: estos géneros son formas representativas de lo que podemos llamar "cancionero criollo norteño". Desarrollaré a continuación algunas de las implicancias identitarias contenidas en esta designación y en esta evaluación de los datos en general.

En efecto, la muchas veces declamada unidad espiritual de todo el folklore nacional no impide el reconocimiento de diferencias identitarias de demarcación bastante nítida desde distintos puntos de vista. El deslinde por regiones es uno de los más obvios y reconocidos explícitamente. Desde este punto de vista, el cancionero que aquí llamo norteño (en referencia al noroeste argentino considerado, para este caso, como una unidad) se distingue, por ejemplo, del litoraleño, propio de las provincias en las riberas del Paraná y en el que reina sobre todo el chamamé, aunque incluye por cierto otras formas, como las chamarritas, el rasguido doble o, incluso, las polcas paraguayas. Es muy usual, por cierto, que, en nombre de la unidad esencial de la nación folklórica, muchos intérpretes incluyan en su repertorio formas provenientes de regiones diversas de las de su lugar de origen. Al mismo tiempo, sin embargo, su identificación regional se expresa, como en el caso del Chaqueño, a través de la predominancia de uno $\mathrm{u}$ otro cancionero. Por cierto, esta circunscripción, identitariamente justificada, puede también asociarse con las relativas limitaciones técnicas que provendrían de la mayor o menor familiaridad que los intérpretes pueden alcanzar con determinados ritmos, como una función de las que están más o menos difundidas y reproducidas en los contextos donde se han formado musicalmente: se entiende, así, que un músico criado en Corrientes, por ejemplo, habrá incorporado mucho más profundamente los matices del chamamé que alguien que ha crecido, por ejemplo, en los Valles Calchaquíes. En estas condiciones, no resulta ofensivo reconocer, por ejemplo, que si el Chaqueño Palavecino interpreta un chamamé, en alguna medida lo "salteñiza" (lo aproxima a las características rítmicas propias de Salta, su provincia natal, entendida así como una unidad identitaria).

Lo de que el cancionero del Chaqueño es no sólo "norteño", sino también predominantemente "criollo", exige otros deslindes, más directamente pertinentes para el tema aquí bajo consideración, pero también de conceptualización más compleja. Observemos, por una parte, que el término arrastra implicancias étnicas: "criollo" se opone, desde este punto de vista, a "indio" y a "inmigrante". Por otra parte, notemos que la expresión "folklore criollo" podría interpretarse como una redundancia: después de todo, el folklore es, por definición, expresión criolla, de modo que no podría haber cancionero folklórico que no fuera también criollo. Sin embargo, la pertinencia de esta calificación puede ilustrarse contrastando el cancionero que estamos analizando con el que podríamos llamar "andino" y que, en términos de género, incluye, por ejemplo, el bailecito, el carnavalito, la cueca 
jujeña (en oposición a la cuyana), el taquirari, el huayno. Este cancionero, de hecho, tiene una interpretación regional, ya que suele reconocérselo como propio de los músicos jujeños (y, por supuesto, de los países andinos como Bolivia y Perú). Pero, además, emerge en su caracterización un componente étnico, ya que a estas formas se les atribuye un origen colla, lo cual nos lleva a la complejas relaciones entre lo indígena y lo criollo.

En el discurso criollista hegemónico consolidado a principios del siglo $\mathrm{XX}$, la incidencia de las culturas originarias se presentaba con una modalidad ambigua, que oscilaba entre la negación lisa y llana de todo valor espiritual del indio, en un extremo, y la asimilación y absorción de sus mejores frutos en el mestizaje del gaucho, en el otro. Probablemente negociando en el interior de esta segunda opción, los ritmos andinos fueron ocupando un espacio cada vez más reconocido en el campo folklórico, en consonancia con la revaloración creciente de la raigambre cultural indígena. De esta manera, hoy en día este cancionero puede interpretarse, al mismo tiempo, como un signo regional jujeño dentro del folklore "criollo" o como una reivindicación étnica desde una perspectiva identitaria india, y ambas perspectivas pueden coincidir en la práctica, incluso sin conflictos, mientras nadie pretenda urgir por definiciones más precisas.

En principio, estas ambigüedades no tendrían que afectar el perfil del repertorio del Chaqueño Palavecino. De hecho, en cierta medida, la incorporación, en proporciones menores, de ritmos andinos, como la cueca popular boliviana "Has visto morir al sol" o el takirari, también boliviano, "Serenata fronteriza", que pueden encontrarse en sus primeros discos, corre pareja con la inclusión, en esa misma etapa, de ritmos litoraleños, como el famoso "Pájaro campana" de Cardozo Ocampo, o los chamamés "Volvé, volvé" y "El alma de Felipito", este último con música registrada bajo la autoría del propio Chaqueño. En esa primera etapa, por otra parte, Palavecino alcanzó un cierto éxito, en ventas de discos y en contratos de actuaciones, en el sur de Bolivia, en la órbita de influencia de Tarija, región en la que, en realidad, existe una difundida afición por el cancionero criollo norteño, la cual, en realidad, atraviesa las fronteras nacionales. Sin embargo, naturalmente, puede comprobarse al mismo tiempo una fuerte presencia del mercado nacional boliviano. Es muy probable que las relaciones artísticas y humanas establecidas por el Chaqueño Palavecino en aquel momento hayan incidido en la incorporación de los dos temas citados a su repertorio.

En líneas generales, puede decirse, en suma, que en los discos publicados hasta 1997, incluida una especie de antología de sus éxitos más importantes, editada el año anterior, el cuadro general del repertorio presenta las características que el Chaqueño había impreso a su primer disco en 1987: una marcada predominancia del cancionero criollo norteño, complementada por la debida y usual proporción de piezas de otros cancioneros. Aunque a lo largo de esa década se producen cambios en otros aspectos, sobre los cuales no elaboraré aquí, puede decirse que este perfil revela la coherencia de la inscripción identitaria del proyecto inicial de nuestro cantor. Quizá sirva entonces también para explicar su reticencia a grabar "Amor salvaje", que le fuera presentado como un "carnaval cruceño", y por lo tanto, en una buena medida, desentonando con esa coherencia.

La clasificación de "Carnaval cruceño", atribuida a "Amor salvaje" por los propios autores de la pieza, merece algunas observaciones, que no resultarán sorprendentes para quienes han escudriñado en la problemática 
de los géneros de la música popular. La expresión cobró resonancia a partir de la grabación del "Carnaval grande", una pieza popular en el oriente boliviano, dando lugar a una forma genérica que se diferencia significativamente de las otras formas andinas que llevan el nombre de "carnaval", fundamentalmente por la subdivisión ternaria, que aproxima al carnaval cruceño más a la polca que al huayno. ${ }^{14}$ De hecho, por un lado, la subdivisión binaria puede considerarse un sello característico de la música andina más vinculada con las culturas originarias. Por otro lado, este aire diferenciador tendería a sellar una cierta oposición identitaria que descansa en el propio mote de cruceño, con su referencia a Santa Cruz y, con ello, al oriente boliviano, en contraste con la adscripción característicamente serrana de la música andina. Es curioso que la pieza que Ternán y Cabrera le presentaron al Chaqueño Palavecino como carnaval cruceño ("Amor salvaje") tiene una subdivisión binaria. No obstante, en efecto, se aproxima a las formas más difundidas del género en la simetría de la estructura rítmica de su melodía, describible como una vertiginosa sucesión de pies yámbicos (en oposición al característico ritmo andino, que, siguiendo con esta metáfora, podría caracterizarse mejor a través del pie métrico del anapesto).

Pero, en todo caso, y más allá de estos matices, tanto el cancionero andino como este carnaval cruceño, al mismo tiempo ligado y distinto de ese cancionero, resulta claramente separable de la marca identitaria del cancionero norteño: tanto la zamba como la chacarera, sus dos géneros más emblemáticos, presentan una curiosa y reconocible característica rítmica, que consiste en el entrecruzamiento, en la misma pieza, y en el mismo compás, de ritmos binarios y ternarios, una complejidad que los practicantes, a través de la reproducción cultural, incorporan desde la más tierna infancia, pero que, por cierto, no es fácilmente asimilable para quienes se aproximan a ella desde otros contextos culturales. En cierto sentido, la relativa simplicidad rítmica (sumada al atractivo vértigo) de "Amor salvaje" permitió al Chaqueño establecer fluido contacto con un público más amplio que el que se sentía inmediatamente identificado con las piezas del cancionero norteño "clásico".

En la historia del repertorio del Chaqueño Palavecino, "Amor salvaje", como señalamos arriba, no es sólo una pieza más, sino que acabó por constituirse en un emblema del propio Chaqueño. Para el momento de su grabación en el disco Salteño viejo, Palavecino ya se había convertido en figura estelar de varios festivales y había comenzado a hacer legendarias sus maratónicas amanecidas en la Serenata de Cafayate. En enero del año siguiente, iba a obtener el premio Consagración del Festival de Cosquín, un trampolín para un crecimiento comercial, que a partir de entonces prosiguió incesante hasta avanzada la primera década del siglo XXI y que de ninguna manera puede decirse que ha cesado por completo hasta nuestros días.. La acogida masiva de "Amor salvaje" fue un ingrediente constitutivo de este proceso, de modo que la imagen ascendente del Chaqueño quedó ligada fuertemente con este carnaval cruceño, que como tal se situaba al margen de su concepción inicial del criollismo. Corresponde señalar que, luego de las mencionadas vacilaciones, el cantor acabó aceptando estas nuevas condiciones, y en los años sucesivos incorporó piezas que cumplían funciones semejantes frente a su público, tales como los carnavales "La ley y la trampa" y "Que me olvides tú" y los takiraris "El dedo en la llaga" y "Celoso no soy". Estos temas tenían varias cosas en común con "Amor salvaje". No sólo suscitaban una activa y más generalizada respues-

${ }^{14}$ Ver Ritmos Sud Americanos (Desde la óptica Andina). Disponivel en <http://pacoweb.net/ Danzas/introri.htm $>$. Acesso en 22 abr. 2017. 
${ }^{15}$ Aunque no conozco estudios sobre el tema, es casi autoevidente que el machismo es francamente predominante en la industria musical del folklore musical argentino. Escasísimas, y muy recientes, son las voces femeninas que hayan emergido como letristas. Y la heterosexualidad es totalmente dominante. De hecho, recientemente, ciertas expresiones homofóbicas del Chaqueño Palavecino en el escenario suscitaron fuertes reacciones en las redes sociales.

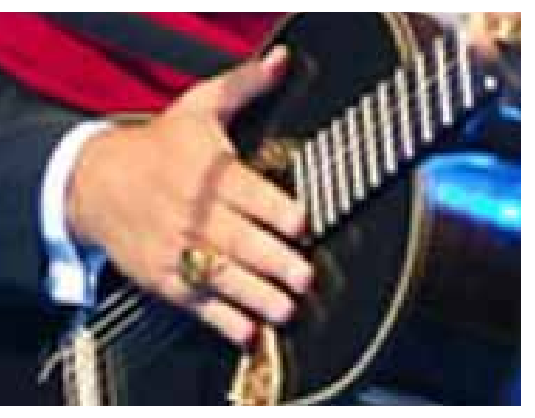

ta de su público en las actuaciones en vivo, sino que además son formas genéricas afines al cancionero andino, pero compuestas por autores cuya obra se articula predominantemente en el cancionero criollo norteño, y en particular en la zamba: Mario Cabrera, Yuyo Montes, Jorge Mlikota, Jorge Rojas y Roberto Ternán. Podría presumirse, en consecuencia, aunque una confirmación más plausible requeriría un estudio más detenido, que los elementos característicamente andinos están en estas canciones reorientados hacia una confluencia con formas más afines al repertorio del Chaqueño, incluso antes de que éste les imprima performativamente su sello particular en interpretación, estilo y sonoridad.

\section{El sexo de los gauchos. La letra de "Amor salvaje"}

Las canciones de amor en el repertorio del Chaqueño Palavecino previo al momento que estamos estudiando se presentan en escasa proporción. Una buena parte de ellas es herencia del repertorio del grupo Los Manseros Santiagueños, con los cuales nuestro cantor mantuvo desde el principio una estrecha relación de apoyo mutuo. Lo predominante en las elecciones del Chaqueño son, en cambio, las letras sobre el paisaje y, sobre todo, los personajes de la gente de su tierra.

Este perfil del repertorio resulta consistente con la imagen pundonorosa ya mencionada que se construyó alrededor del gaucho en el discurso de la generación del Centenario, sobre todo a partir de El payador de Leopoldo Lugones, libro en el que recopiló una serie de conferencias que dictó en Buenos Aires en 1910 ante un público que incluía las figuras más representativas del poder político y social argentino del momento y que constituyó una de las referencias clave en la construcción del Martín Fierro como epopeya fundacional y del gaucho como epítome de la esencia nacional argentina. Lugones dedica uno de los capítulos extensamente a desarrollar la imagen galante del gaucho, respetuoso del honor de su compañera y extremadamente púdico en la expresión de los sentimientos. En las expresiones de arte popular que cita, no figuran, por cierto, las coplas picarescas y de doble sentido erótico que, en cambio, sí aparecen profusamente en los cancioneros recogidos por otros autores $\mathrm{y}$, de todos modos, la descripción nos resulta por lo menos sospechosa en vista del secular patriarcado que sigue hasta el día de hoy vigente en la mayor parte de la cultura campesina criolla. Sin embargo, la imagen pergeñada por Lugones campeó exitosamente al menos en la retórica del folklore tradicional argentino y encontró eco en el propio Atahualpa Yupanqui, que produjo muy escasas canciones de amor, o introdujo el tema en algunas de sus canciones con referencias efectivamente sutiles y delicadas. Aun entre autores de generaciones posteriores, las canciones de amor, aunque quizá proliferaron en mayor medida, conservaron de todos modos el tono de exaltación cortesana de la amada ${ }^{15} \mathrm{o}$ un poético lamento por la distancia o el fin del amor.

A lo largo de los 1990, algunas expresiones del folklore, sobre todo entre intérpretes vinculados a un público juvenil, ciertamente, comenzaron a transgredir flagrantemente este paradigma, como en el caso de los Nocheros, ácidamente cuestionados por los defensores de la tradición anterior. El Chaqueño Palavecino, hasta la incorporación de "Amor salvaje", como queda dicho, se había mantenido fiel a la imagen lugoniana (al menos en la elección del repertorio, ya que, como hemos señalado, en sus actuaciones 
públicas, tuvo siempre una tendencia a deslizar afirmaciones menos caballerescas sobre las damas, siempre en tono jocoso y de confianza, aunque a veces lindante con la chabacanería). Resulta sintomática la expresión del Chaqueño cuando los autores de "Amor salvaje" le propusieron por primera vez la pieza, según testimonio personal del compositor: "Cómo va a cantar algo así un gaucho". ${ }^{16}$ La letra de "Amor salvaje", en efecto, no sólo tiene como tema central el amor, sino que además contiene contenido sexual explícito y de ardientes metáfora y, sobre todo, describe una relación amorosa fugaz y casual, puramente carnal:

\author{
"Amor salvaje"17 \\ Letra: Roberto Ternán / Música: Mario Oscar Cabrera
}

Te llevé sin preguntarte ni tu nombre, con mi brazo encadenado en tu cintura.

Asalté tu intimidad y tu ternura

para amar sin más razones que el amor.

Nos besamos sin decir una palabra.

Fuimos cómplices callados del verano.

$Y$ mis manos temblorosas se quemaron

seducidas por el fuego de tu piel.

Amor salvaje,

juntos cruzamos los umbrales del pecado.

Con el puñal de la pasión nos desgarramos

sin derramar ni una gotita de dolor.

Amor salvaje,

como una selva tropical nos incendiamos

en un instante sin saber que no dejamos

ni una ramita de ilusión para después.

Anhelante como un puma entre las sombras,

desgajé tu cuerpo entero con mis besos,

atrapado por las lunas de tu pecho,

por el cálido gemido de tu voz.

$Y$ montados en el potro del deseo

sin fronteras por la noche galopamos

y nos vio la madrugada con ojeras

desvelados diciéndonos adiós.

\author{
Amor salvaje, \\ juntos cruzamos los umbrales del pecado, \\ con el puñal de la pasión nos desgarramos \\ sin derramar ni una gotita de dolor. \\ Amor salvaje, \\ como una selva tropical nos incendiamos \\ y en un instante sin saber que no dejamos \\ ni una ramita de ilusión para después
}

${ }^{16}$ Las declaraciones del compositor Roberto Ternán fueron tomadas en una entrevista personal en junio de 2008.

17 Traducción de María Laura Rojas Moreno: "Amor salvagem": "Te levei sem perguntar sequer teu nome,/ com o meu braço acorrentado à sua cintura./ Invadi sua privacidade e sua ternura/ Para amar sem mais razões do que o amor.// Nos beijamos sem dizer uma palavra./ Fomos parceiros silenciosos do verão./ E minhas mãos trêmulas foram queimadas/ seduzidas pelo fogo da sua pele.// Amor selvagem,/ Juntos atravessamos os portões do pecado./ Com o punhal da paixão nos rasgamos/ sem derramar uma gota de dor.// Amor selvagem,/ como uma floresta tropical nos incendiamos/ num instante sem saber que não deixamos/ nem um raminho de ilusão para depois./ Desejando-te como um puma nas sombras,/ Desnudei todo o seu corpo com meus beijos,/ preso pelas luas de seu peito,/ pelo grito quente da sua voz.// E montado no potro do desejo/ galopamos à noite sem fronteiras/ e a madrugada nos viu com olheiras/ nos dizendo adeus.// Amor selvagem,/ juntos atravessamos os portões do pecado,/ com o punhal da paixão nos rasgamos/ sem derramar nem uma gota de dor.// Amor selvagem,/ como uma floresta tropical nos incendiamos/num instante sem saber que não deixamos/nem um raminho de ilusão para depois." 
${ }^{18}$ Traducción de María Laura Rojas Moreno: "A menina de Cerrillos": Com a saia curta/ e as tranças longas eu vi você passar/ como rainha nas tendas/ nessa tarde de carnaval/ e nesse instante/ Eu desci do meu cavalo.// Eu desmontei o meu cavalo/ e cheguei perto para olhar./ Com a alma num fio,/ Minha morena linda, eu vi você dançando./ Quando a dança acabou/ eu lhe ofereci uma cerveja.// Como esquecer você, Cerrillos,/ se graças a você tenho uma esposa./ Morena cerrillana,/ Com minha alma e minha vida eu te cantarei./ Todos os carnavais/ para Cerrilos vou te levar.// Logo seguiram as zambas,/ dançamos juntos, sem descanso,/ entre fogos e serpentinas do carnaval,/ até que a manhã chegou/ cantando uma baguala.// Quarta-feira de cinzas/ cheios de farinha nos viu passar./ Você esqueceu do seu pai / para vir comigo/ e nas ancas do meu cavalo/ fomos para meu rancho.// Como te esquecer, Cerrillos,/ se graças a você eu tenho uma esposa./ Morena cerrillada,/ com minha alma e minha vida eu te cantarei./ Todos os carnavais / para Cerrilos vou te levar.
Este cuadro contradice abiertamente los principios morales tradicionalmente supuestos en el folklore anterior, como los que se canalizan, por ejemplo, en otra zamba de larga tradición en el folklore comercial argentino, "La cerrillana", del repertorio de los Chalchaleros, en la que se da cuenta de una relación de pareja que comienza, de manera semejante, tras conocerse en una fiesta, pero que culmina en la permanencia del matrimonio, según se ocupa de reafirmar el propio estribillo de la canción:

\author{
"La cerrillada"18 \\ Letra: Abel Mónico Saravia / Música: Marco Tames
}

Con la pollera yuta, las trenzas largas te vi pasar

como reina en las carpas

en esa tarde de carnaval

y ahí nomás a mi zaino

en el guardapatio lo hice rayar.

Desmonté del caballo,

me puse cerca pa' mosquetear.

Con el alma en un hilo,

mi negra linda, te vi bailar.

Cuando terminó el baile

una cerveza te fui a brindar.

Cómo olvidarte, Cerrillos,

si por tu culpa tengo mujer.

Morena cerrillana,

con alma y vida te cantaré.

Todos los carnavales

para Cerrillos te llevaré.

Luego siguieron zambas,

bailamos juntos sin descansar,

entre medio'e los cohetes

y serpentinas del carnaval,

hasta que llegó el alba

con la baguala dele cantar.

Miércoles de ceniza

enharinados nos vio pasar.

Olvidaste a tu tata

para seguirme, palomitay,

$y$ en ancas de mi zaino

luego a mi rancho fuimos a dar.

Cómo olvidarte, Cerrillos,

si por tu culpa tengo mujer.

Morena cerrillana,

con alma y vida te cantaré.

Todos los carnavales

para Cerrillos te llevaré. 
Al parecer, el Chaqueño aceptó inicialmente la sugerencia de la inclusión de la pieza, siempre según el testimonio del compositor, frente al argumento de que la letra planteaba su relato de una manera tan exagerada que daba lugar a una interpretación humorística, cosa que admiten también muchos de los testimonios que he recogido. No obstante, es importante anotar que en el repertorio posterior del Chaqueño, se incorporaron otras piezas que también proponen transgresiones a la moral tradicional (aunque quizá ninguna en el grado de "Amor salvaje") y que, como en los casos ya mencionados, pasaron a formar parte de la sección más festiva de sus presentaciones: "Celoso no soy", "La ley y la trampa", "Dejame que me vaya”.

El estudio del caso de la incorporación de "Amor salvaje" en el repertorio del Chaqueño Palavecino nos da pie para avanzar hipótesis sobre la composición identitaria del público masivo de la industria del foklore musical argentino (en probable contagio de otras industrias musicales.) La ampliación del público, en efecto, implica un desdibujamiento del perfil del proyecto original del cantor, que persiste sólo como un núcleo central sobre el cual se acoplan un conjunto de opciones más diversificadas: a) una "fiesta" más englobadora (de llegada a más cuerpos); b) una interpretación menos "ortodoxa" de la música propiamente "folklórica"; c) nuevas resoluciones de tensiones latentes (como la de la moral sexual).

Quisiera al menos dejar esbozadas, finalmente, algunas de las variables que he encontrado como significativas para encarar una explicación sociológica de la heterogénea composición del público masivo conformado alrededor del Chaqueño Palavecino, y que se cruzan en distintos grados y de distintas maneras en las subjetividades de los actores comprometidos en esta amplísima comunidad. Me parece importante señalar en primer lugar que, sobre todo entre los actores de mayor edad, la imagen propiamente criollista del Chaqueño sigue siendo un elemento sustancial de afinidad, un lazo muchas veces profundizado, en contraste con otras opciones del mercado de la industria del folklore musical argentino, por la afinidad de clase. En distintos grados, esta aceptación se complementa, en la mayoría de mis entrevistada/os, con la aceptación de la fiesta "descomprometida" que se incorpora con "Amor salvaje", sea como una resignación negociada o, más generalmente, entre los jóvenes, como una especie de modernidad que, a menudo, se erige como el atractivo original, dentro del cual el criollismo juega un papel de telón de fondo, aunque de ninguna manera descartable. Como si de alguna manera, la valoración del criollismo siguiera convocando sus lealtades, cien años después de su negociada entronización.

Artigo recebido em março de 2017. Aprovado em abril de 2017. 